\title{
Hand injury: association of handedness with cause and site of injury
}

W. Kaisha, MBChB (UoN), MMed (Surg), Assistant Lecturer, Department of Human Anatomy, University of Nairobi, and Senior Registrar of Surgery, Kenyatta National Hospital, P.O. Box 368-00202, Nairobi, Kenya, S. Khainga, MBChB (UoN), MMed (Surg), Lecturer, Department of Surgery, University of Nairobi, and Consultant Surgeon, Kenyatta National Hospital, P.O. Box 30197, Nairobi, Kenya

Correspondence to: Dr. W. Kaisha, Department of Surgery, Kenyatta National Hospital, P.O. Box 36800202, Nairobi, Kenya, Email: wyksa2000@uonbi.ac.ke

\section{Abstract}

BACKGROUND: Most peoplehave a dominant hand: right or left. The dominant hand for most purposes is that which is used for writing. The performance, reflex activity and exposure of these hands differ. Due to this asymmetry, it is possible that handedness may influence the likely causes, the lateralization and pattern of injury.

OBJECTIVE: This study was designed to assess the association of hand dominance to the causes, lateralization and pattern of hand injuries.

SETTING: Kenyatta National Hospital, a national referral and teaching hospital in Nairobi, Kenya.

METHODOLOGY: A prospective analysis of consecutive patients who presented with unilateral hand injuries between May and August 2006 at $(\mathrm{KNH})$ was done. Data on hand dominance, hand injured, causes and pattern of injury were collected using a questionnaire. Associations were investigated using student's t-test and Chi square tests, with level of significance taken as $\leq 0.05$. Yates correction and Fischer's exact tests were used where the cell value was less than 5 .

RESULTS: A total of 99 patients with hand injuries were recruited. Ninety four were right handed, three left handed, with two ambidextrous. The dominant hand was injured in $47(48.5 \%)$, while the non-dominant hand was injured in $51.5 \%$ of the cases $(p=0.27)$. The most common causes of injury were occupational (31.3\%) and assaults (30.3\%). Falls on the hand caused injury more on the dominant hand $(p=0.03)$ than the non-dominant one. Hand dominance had no influence on the other causes, nor did it have influence on the lateralization and pattern of injury.

CONCLUSION: With the exception of falls, hand dominance has no influence on causes, lateralization and pattern of hand injury.

\section{Introduction}

Hand injuries are common and may account for $5-10 \%$ of emergency department admissions (1). The injury may be unilateral or bilateral. Several studies have assessed the correlation between hand dominance and lateralization of injury(26) with some suggesting that hand dominance influences lateralization of injury (2-5), while others disagree $(3,6)$. However, the effect of handedness on site and pattern of injury has not been described.

An individual's handedness can be determined by observing hand use during various tasks (7). The hand preferred for use 
during most tasks is considered to be the dominant one. Various tests, with a score obtained can be employed to determine handedness, but writing is the activity that best predicts handedness (7).

\section{Methodology}

The study was conducted among consecutive patients with acute unilateral hand injuries who presented at $\mathrm{KNH}$ Accident and Emergency (A\&E) department between May 2006 and August 2006. To be eligible for the study, subjects must have had an injury involving any part of the hand, hand being considered to be any part distal to the distal wrist crease. Patients excluded were those with: burn injuries, previous hand injuries and bilateral injuries.

The study was approved by the KNH Ethics and Research Committee. Informed consent was sought from the participants of this study. A questionnaire was used to extract data at the A \& E department.

Statistical Package for Social Sciences (SPSS) 11.5 (Chicago-Illinois) software was used for data entry and analysis. Associations were investigated using the student's t-test, the Chi-square test with level of significance taken as $\leq 0.05$. Yates correction and Fisher's exact tests were used where the expected cell value was less than 5 .

\section{Results}

A total of 99 patients were recruited into the study. Ninety four (95\%) were right handed while $3(3 \%)$ were left handed with the ambidextrous group forming $2 \%(n=2)$. The dominant hand and non-dominant hands were injured in almost equal proportions. Comparing the individual's handedness and the hand injured, those who were right handed had the dominant hand injured in 44 cases (46.8\%) while the non-dominant hand was injured in 50 cases $(53.2 \%)$. Those who were left handed had only their dominant hand injured. There was no difference between the likelihood of the dominant hand and the non-dominant hand being injured $(\mathrm{P}=0.27)$.

The most common cause of injury was work (while operating any form of equipment) or machinerelated (occupational). This represented $31.3 \% \quad(n=31)$ of the patients, followed by assaults, which affected 30 patients (30.3\%). Falls caused injury in 10 patients $(10.1 \%)$ and hand being caught in objects affecting 8 patients $(8.1 \%)$ which was similar in prevalence to road traffic accidents (Table 1). The distribution of the causes of injury was similar for the dominant and non-dominant hand except for falls. The dominant hand was twice as likely to be injured in a fall compared to the non-dominant hand (p-value 0.003, RR 1.78).

Table 1: Influence of hand dominance on cause of injury

\begin{tabular}{|lcccc}
\hline Injured hand & Dominant, $\mathrm{n}$ & Non-dominant, $\mathrm{n}$ & $\mathrm{RR}^{*}$ & $\mathrm{p}_{\text {-value }}^{*}$ \\
\hline Injury at work/machinery & 14 & 17 & 0.90 & 0.65 \\
Assault & 15 & 15 & 1.05 & 0.83 \\
Fall on hand & 8 & 2 & 1.78 & 0.03 \\
Road traffic accident & 4 & 4 & 1.03 & 0.60 \\
Hand caught between objects & 3 & & 0.76 & 0.39 \\
Sports related & 1 & 3 & 11.03 & 0.73 \\
Cutting/piercing & 0 & 1 & - & 0.14 \\
Knife injury & 1 & 0 & 2.03 & 0.73 \\
Broken glass & 1 & 3 & & 0.48 \\
Other & 1 & & &
\end{tabular}


Table2: Site and pattern of injury

\begin{tabular}{|c|c|c|c|c|}
\hline Injured hand & Dominant, $n$ & Non-dominant, $\mathrm{n}$ & $\mathrm{RR}^{*}$ & $p$-value* \\
\hline \multicolumn{5}{|l|}{ Site } \\
\hline Thumb & 8 & 8 & 1.00 & 0.99 \\
\hline Index & 11 & 11 & 1.02 & 0.93 \\
\hline Long & 11 & 12 & 0.96 & 0.88 \\
\hline Ring & 11 & 15 & 0.81 & 0.42 \\
\hline Little & 7 & 6 & 1.08 & 0.81 \\
\hline Carpus & 15 & 17 & 0.95 & 0.82 \\
\hline \multicolumn{5}{|l|}{ Pattern } \\
\hline Integument & 34 & 43 & 0.71 & 0.17 \\
\hline Phalangeal fracture & 29 & 26 & 1.10 & 0.50 \\
\hline Metacarpal fracture & 7 & 12 & 0.67 & 0.20 \\
\hline Joints & 5 & 4 & 1.08 & 0.56 \\
\hline Tendons & 10 & 11 & 0.95 & 0.85 \\
\hline
\end{tabular}

The most predominant site of injury was the carpus, $28 \%$ (hand minus the digits). Among the fingers, the ring was the most commonly injured $(23 \%)$ with the little finger being least injured (11.6\%). Most patients had open injuries, with integument being the most affected structure, followed by fractured bones. Of the bones, the phalanges were the most affected. The distribution of injuries according to the site and pattern of injuries versus the hand injured are shown in Table 2. The regional distribution of injuries was similar for dominant and nondominant hands.

\section{Discussion}

The present results have shown that the dominant and non-dominant hands were injured in almost equal proportions and that handedness was not predictive of the increased likelihood of one hand being injured. This compares well with the study by Shaheen et al in Qatar and Mink in the USA (4) but at variance with that of Porac (3) in a study in Canada, and Hill (6) in Ireland, who found that individuals with consistent hand preference were more likely to injure their dominant hand.

This study has also found that work-related injury and assaults were the most common causes of injury to the hand. This patterns may reflect the socioeconomic state of the victims and the country's level of development. Compared to a country like Qatar (5), this differs greatly as industrial causes accounted for $59 \%$ with domestic and recreational (sports injury) being next (30\%). When correlated with handedness, there was no statistical difference in the distribution of most causes between dominant and non-dominant hands. Only where injuries resulted from falls, was the risk of injury to dominant hand significant. Hill et al reported the dominant hand as being more susceptible to injuries resulting from opening doors, opening tins, broken glass and falls, while the non-dominant hand waas largely affected by knife injury. His findings partly agree with this study in as far as the effect of falls on the dominant hand are concerned. Although the results were insignificant in our study, the relative risks of injury to the non-dominant hand was higher when the cause was the hand being caught in objects when compared to the dominant hand. Mackenzie and Peters (8) explained increased susceptibility of non-dominant hand to injury from hand held objects such as knifes. They noted that if the instrument is held in the dominant hand, it is the other hand that will be most prone to injury. Injury at work and assaults in the current study affected both the dominant and nondominant hands equally, which is in agreement with findings of other authors $(6,8)$. However, Hollies (9) did not find any difference between dominant and non-dominant hand whatever the mechanism of injury. 
There was no difference in the distribution of sites of injury between the dominant and nondominant hands. The relative risk of any part of the hand being injured between dominant and non-dominant hands was the same, save for the little finger where risk for injury to the non-dominant one was relatively higher. Our findings compare well with those of Ljungberg et al (10) who did not find any difference in injury localization between the right and left hands. This similarity in site and pattern of injury distribution between dominant and nondominant hands can be explained by the lack of selectivity in lateralization of injury. Because none of the hands is at higher risk it follows therefore the rest of localization and pattern would largely be similar.

\section{Conclusion}

Handedness does not appear to influence the lateralization and pattern of hand injury. With the exception of falls, hand dominance does not also influence the cause of injury.

\section{References}

1. Antosia R.E. and Lyn L. The hand in emergency medicine. Concepts Clin. Pract. 1998; IV: 625-668.
2. Taras J.S., Behrman M.J. and Degnan G.G. Left-hand dominance and hand trauma. J. Hand Surg. [Amer]. 1995; 20: 1043-1046.

3. Porac C. Hand preference and the incidence of accidental unilateral hand injury. Neuropsychologia. 1993; 31: 355-362.

4. Mink Van Der Molen A.B., Matloub H.S., Dzwerzynsk W., et al. The hand injury severity scoring system and workers compensation cases in Wisconsin, USA. J. Hand Surg. [Brit]. 1999; 24B: 2: 184-186.

5. Shaheen T., Khalid K.N. and Basti H. Epidemiology of hand injury in Qatar. The Middle East J. Emerg. Med. 2003; 3: 1-5.

6. Hill C., Riaz M., Mozzam A., et al. A regional audit of hand and wrist injuries: A study of 4873 injuries. J. Hand. (Brit). 23B: 2: 196-200.

7. Corey D.M., Hurley M.M. and Foundas A.L. Right and left handedness defined: A multivariate approach using hand preference and hand performance measures. Neuropsychol. Behav. Neurol. 2001; 14: 144-152.

8. Mackenzie K. and Peters M. Handedness, hand roles, and hand injuries at work. J. Safety Res. 2000; 31: 221-227.

9. Hollies L.J. The relationship between handedness, mechanism of injury and which hand injured. J. Hand Surg. 1993; 18B: 394.

10. Ljungberg E., Rosberg H.E. and Dahlia L.B. Hand injuries in young children. J. Hand Surg. 2003; 28B: 4: 376-380. 